\title{
Design e inovação: mapeamento e análise nas indústrias do Rio Grande do Norte ${ }^{1}$
}

Design and innovation: mapping and analysis of Rio Grande do Norte industries

ALVES, Cristiano I Doutor em Engenharia Mecânica

Universidade Federal de Santa Catarina - UFSC I cralves@dcdesign.com.br

ALVES, Daniela Estaregue I Doutoranda em Design

Universidade Federal de Santa Catarina - UFSC I daniesta@gmail.com

MACEDO, Susie I Administradora SENAI/RN

SENAI - Departamento Regional do Rio Grande do Norte I susie@rn.senai.br

ALVES, Tuisi I Bacharel em Design

Universidade Federal do Rio Grande do Norte - UFRN I tuisialves@yahoo.com.br

GONCCALVES, Marília Matos I Doutora em Engenharia de Produção

Universidade Estadual de Santa Catarina - UFSC I marilinhamt@gmail.com

\begin{abstract}
Resumo
O presente trabalho avalia o nível de sensibilização e conscientização das indústrias do RN a respeito do design e suas vantagens estratégicas de negócio, por meio de aplicação de questionários direcionados aos empresários. Os resultados apontam para o baixo nível de conhecimento da atividade de design e pouca aplicação nas atividades industriais locais.

\section{Abstract}

This paper aims to assess - through questionnaires targeted to entrepreneurs - the level of sensibility and consciousness regarding design and its strategic advantages to business in Northeast Brazilian industries. Results reveal the lack of design activity and little concern of application within local businesses.
\end{abstract}

Palavras-chave: Gestão. Design. Indústria. Gestão da inovação.

Keywords: Management. Design. Industry. Innovation management.

1 Os autores agradecem a CAPES, ao CNPq e a UFRN pelo apoio financeiro via bolsas de estudo e, a FIERN/SENAI pela parceria e fornecimento de dados para a realização da pesquisa.

Projética, Londrina, v.8, n.2, p. 127-143, Jul./Dez. 2017 


\section{INTRODUC̣ÃO}

Atualmente, qualidade e preço não são mais considerados diferenciais e sim pressupostos, enquanto design, inovação e sustentabilidade consolidamse como diferenciais decisivos para a competitividade, com o design ganhando maior destaque no mercado atual. Entretanto, no Rio Grande do Norte (RN), percebe-se que o termo "design" ainda é banalizado e o potencial da atividade é desconhecido. Segundo Marques (2010), o entendimento sobre o design é variado, sendo utilizado por diferentes pessoas, em aplicações distintas e com diferentes significados. Tido como o explorador, que percebe o design como uma "droga milagrosa" para aumentar vendas, um refinamento, uma bela aparência, encobrindo o baixo valor de uma mercadoria para elevar seu valor de troca. Uma visão simplista que reduz o design ao aspecto estético, não abrangendo suas funções, atividades, técnicas, ideias e valores além da estética do produto. Para Mozota (2003), devido à falta de compreensão do design os gestores das empresas têm dado pouca importância à atividade. Diante disso, pergunta-se: qual é a compreensão das indústrias do RN sobre a atividade de design e sua abrangência estratégica para seus respectivos negócios?

Assim, procura-se avaliar o grau de conscientização das indústrias do Rio Grande do Norte (RN) com relação ao design e suas vantagens estratégicas para o negócio, tendo como objeto de estudo as indústrias da construção civil, alimentícia e têxtil/confecções, do Estado. Busca-se também, contribuir para estudos futuros sobre o tema, visto que, o estudo pretende traçar um perfil que identifique os pontos a serem trabalhados para a inserção ou expansão do design nesses setores, como também na indústria como um todo.

\section{DESIGN E INOVAC̣ÃO}

Design e inovação são processos complementares, com interações e sinergias com o objetivo principal de mudar constantemente a cultura e base material das sociedades (BENAVIDES, 1999). Portanto, possuem diversos fatores comuns, lidando com atividades multidisciplinares inerentes ao processo projetual, como: planejamento, criatividade, tecnologia, experimentos, produção e mercado. Assim, tais atividades são orientadas para o futuro e agentes de mudanças sociais. Portanto, o design insere-se como parte integrante do processo de inovação, conduzindo conceitos e invenções até sua aplicação mercadológica. No contexto sinérgico e dinâmico da inovação, o design, deve ser considerado como instrumento de promoção da qualidade e da tecnologia no desenvolvimento dos produtos, como parte fundamental do avanço tecnológico (BENAVIDES, 1999). 
Segundo Bonsiepe (2015), o design, juntamente com a tecnologia e a ciência, são fatores decisivos no processo de inovação. Assim, o design aparece como elemento de união entre áreas do saber e permite a integração da inovação na prática da vida cotidiana. Para o estabelecimento de um processo efetivo de excelência em inovação, é fundamental a interação entre design, tecnologia e ciência. Portanto, a consolidação da abordagem do design na cultura empresarial e social do RN tem enorme potencial em incrementar o desenvolvimento do Estado em aspectos econômicos, técnicos e socioambientais.

Mesmo pouco percebido, o design está inserido no cotidiano das sociedades. Em toda manipulação de objetos nos deparamos com o design, tornando essencial para o sucesso e manutenção dos produtos no mercado. Segundo pesquisa da Confederação Nacional das Indústrias (CNI), o design traduz-se em diversos benefícios para as empresas, tais como: imagem institucional, otimização de custos, aumento da competitividade e, consequentemente, exportações. Além de que, cada dólar investido em design, gera cinco dólares de retorno (RAULIK, 2003).

Design é diferente de estilo. Enquanto o estilo manifesta-se apenas na aparência do produto, sem traduzir melhoria de desempenho, o design afeta também a utilidade do produto. Do ponto de vista do marketing, o design é a forma de diferenciar o produto de uma empresa, atraindo a atenção do consumidor, melhorando o desempenho do produto ou reduzindo os custos de fabricação (SEBRAE, 2005). O design contribui com valores tangíveis e intangíveis de uma empresa, seja pela concepção da marca, desenvolvimento de produto, incorporação das necessidades dos usuários, compreensão das percepções dos usuários com relação aos atributos do produto, viabilidade produtiva, dentre outros aspectos. Sua abrangência vai desde a concepção, passando por diversas fases, até a entrega ao cliente.

Figura 1 - Níveis de utilização do design
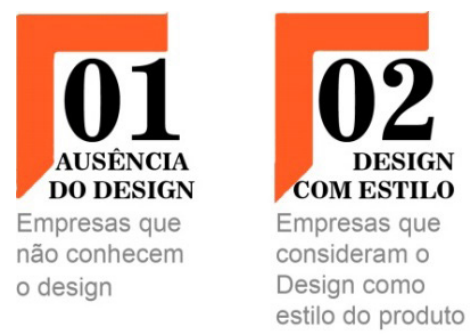
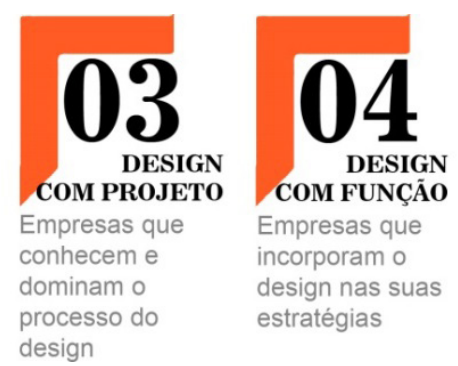

Fonte: Adaptado de Rede Design Brasil (2005)

A atuação do design não se limita a criação de produtos e ela tornase parte de um sistema consolidando-se como processo de gestão. Como simplificado na Figura 1, um modelo para categorizar a utilização do design pelas empresas em quatro níveis (REDE DESIGN BRASIL, 2005). 
Como estratégia de inovação e competitividade, o design tem apresentado evolução em suas abordagens que, acompanham a evolução tecnológica e social ao longo dos anos. Portanto, especializando-se em integrar aspectos socioambientais nos projetos, o que implica mudança de posturas e objetivos, emergindo assim, o design sustentável.

\section{DESIGN E A INDÚSTRIA DO RIO GRANDE DO NORTE}

Apesar da evidente importância do design como catalisador de inovação, o mesmo é, muitas vezes, negligenciado por pequenas empresas. Segundo pesquisa realizada pelo SEBRAE e pela CNI, em 2003 apenas $42 \%$ e $45 \%$ de micro e pequenas empresas, respectivamente, investiram em design. A pesquisa apontou que as abordagens metodológicas do design têm pouca relação com suas realidades (CONFEDERAÇÃO NACIONAL DA INDÚSTRIA, 1998). Segundo a Associação dos Designers de Produto (ADP), através do Programa Brasileiro de Design (PBD), as Pequenas e Médias Empresas (PMEs) percebem o design apenas como qualidade estética dos produtos e serviços, desconhecendo seu aspecto estratégico ao negócio, que é uma das diretrizes da gestão de design. Design é um dos recursos que auxilia as empresas a aumentar sua eficiência, inovar e manterem-se competitivas (SEBRAE, 2005). Segundo Raulik (2003), empresas de pequeno porte, esperam por resultados imediatos e são orientadas para curto prazo.

Os dados citados acima apontam para o potencial de desenvolvimento e expansão do design no RN, uma vez que seu perfil industrial é formado, basicamente, por PMEs e, portanto, com poucos investimentos e conhecimentos sobre os benefícios do design. Segundo a Federação das Indústrias do Estado do Rio Grande do Norte (2012), o perfil das indústrias do estado é composto por $99 \%$ de PMEs. Assim, é possível verificar o enorme potencial que o design possui para promover a inovação destas empresas e, consequentemente do RN, como estratégia de incremento da inovação, da competitividade e principalmente, um transformador social.

\section{METODOLOGIA}

Para alcançar os objetivos, optou-se por uma pesquisa quantitativa. Assim, foi desenvolvido e aplicado um questionário com 04 perguntas fechadas, de múltipla escolha e de graduação de opinião. A aplicação se deu com indústrias do RN dos setores de alimentos, têxtil e construção civil, cadastradas no banco de dados da FIERN. A escolha dos setores foi baseada em dados fornecidos pela FIERN (Federação das Indústrias do Estado do Rio Grande do Norte), segundo os quais, apontam que tais setores inferem significativamente nos indicadores socioeconômicos do estado, representam alto percentual do PIB do RN e grande geração de empregos. Foram entrevistadas 60 empresas sendo 35 do setor de alimentos, 14 têxtil e 11 da construção civil. Os questionários foram enviados por meio digital, diretamente, aos respectivos empresários e/ou responsáveis 
pelas decisões estratégicas das empresas. Tal questionário foi enviado e respondido no período de Setembro de 2014 a Março de 2015 e, composto por 4 perguntas nas quais, as empresas atribuem graus de importância a atividades e processos referentes às suas respectivas cadeias de valores (pergunta 01). Assim, é possível perceber a importância dada aos mesmos e/ou a ausência de conhecimento sobre estes e, portanto, o potencial de interesse das empresas em investir nos itens relacionados. Na pergunta 02 , as empresas atribuem graus de importância, para seus respectivos negócios, de atividades relacionadas a serviços e técnicas/ferramentas de adição de valores que o design pode agregar aos seus produtos. Com tais perguntas sobre percepção de atividades processuais gerais, assim como serviços e técnicas como foco ao negócio, é possível apontar a importância dada aos itens relacionados nas perguntas ou mesmo o desconhecimento destes e, portanto, o potencial de interesse em investir nos mesmos, assim como perceber o potencial de inovação destas empresas, uma vez que tais itens referem-se à atividades que potencializam a inovação industrial.

Com o intuito de analisar o grau de compreensão das empresas em relação a abrangência de seus respectivos produtos e perceber o potencial do design em promover inovação e incremento da competitividade, as empresas foram interrogadas sobre o que oferecem ao mercado (pergunta 03). Finalmente, as empresas foram questionadas a apontar sua compreensão sobre a abrangência das atividades desempenhadas pelo design, havendo a possibilidade de escolha de mais de uma alternativa (pergunta 04). Assim, foi possível verificar quão abrangente é compreensão das empresas sobre o design e suas atividades (operacionais, táticas e estratégicas), assim como sobre seus próprios produtos, ou seja, em percebê-los além do objeto tangível (manufaturado), visualizando-os também como provedores de serviços diversos e, portanto, potencializando a inovação e a competitividade.

Deste modo, os resultados foram analisados relacionando os resultados obtidos nas das percepções das empresas referentes à importância dos processos e técnicas e ferramentas (perguntas 1 e 2). E ainda foram relacionadas com a percepção das empresas da abrangência de seus respectivos produtos e, finalmente, desenvolveu-se uma relação dessas respostas com a percepção das empresas sobre a atividade de design. Em determinadas análises a variável "Design" foi isolada para melhor compreensão desta variável em relação a cada setor de mercado analisado. Nas análises dos resultados serão explanados maiores detalhes das análises.

\section{ANÁLISE DOS RESULTADOS}

\subsection{A Importância de Atividades e Processos da Cadeia de Valor}

Na primeira etapa do questionário, as empresas foram solicitadas a atribuir grau de importância de atividades e processos referentes às 
suas respectivas cadeias de valores no intuito de obter das empresas, uma percepção geral do que consideram fundamental para a geração de valor em seus respectivos nichos de mercado.

A figura 2 expõe os resultados dessa primeira etapa onde é possível perceber que produção e logística foram consideradas muito importantes para $90 \%$ e $86,67 \%$ das empresas, respectivamente, seguidos de segurança (78\%), qualidade e meio ambiente (75\%), inovação (73,33\%) e informática (70\%). Por outro lado, engenharia (43,33\%), prototipagem (23,33\%), SAC (43,33\%), ergonomia (35\%) e embalagem (48,33\%), apresentaram baixo índice de importância, considerados importantes por menos da metade das empresas. 0 item prototipagem apresentou o maior percentual de desconhecimento, sendo sua importância considerada desconhecida por 35\% das empresas. É possível observar qualidade e meio ambiente são importantes para 75\% das empresas, entretanto essa resposta pode ser contestada em questões posteriores.

Referente ao design, 58,33\% das empresas o considera muito importante $21,67 \%$ consideram de importância razoável, 13,33\% consideram pouco importante e 6,67\% desconhecem sua importância. Assim, é possível verificar considerável diferença entre os itens Inovação e Design, pois alguns empresários ainda não associam diretamente o design ao processo de inovação, sendo que estes itens estão diretamente relacionados. O design é essencial à inovação, sendo indispensável que as empresas aprendam a gerenciá-lo no contexto deste processo (MOZOTA; KLÖPSCH; COSTA, 2011). Para tal, é necessário que elas reconheçam essa relação e que o design ultrapasse os níveis meramente operacionais dentro dessas organizações.

Figura 2 - Para sua empresa qual a importância desses itens?

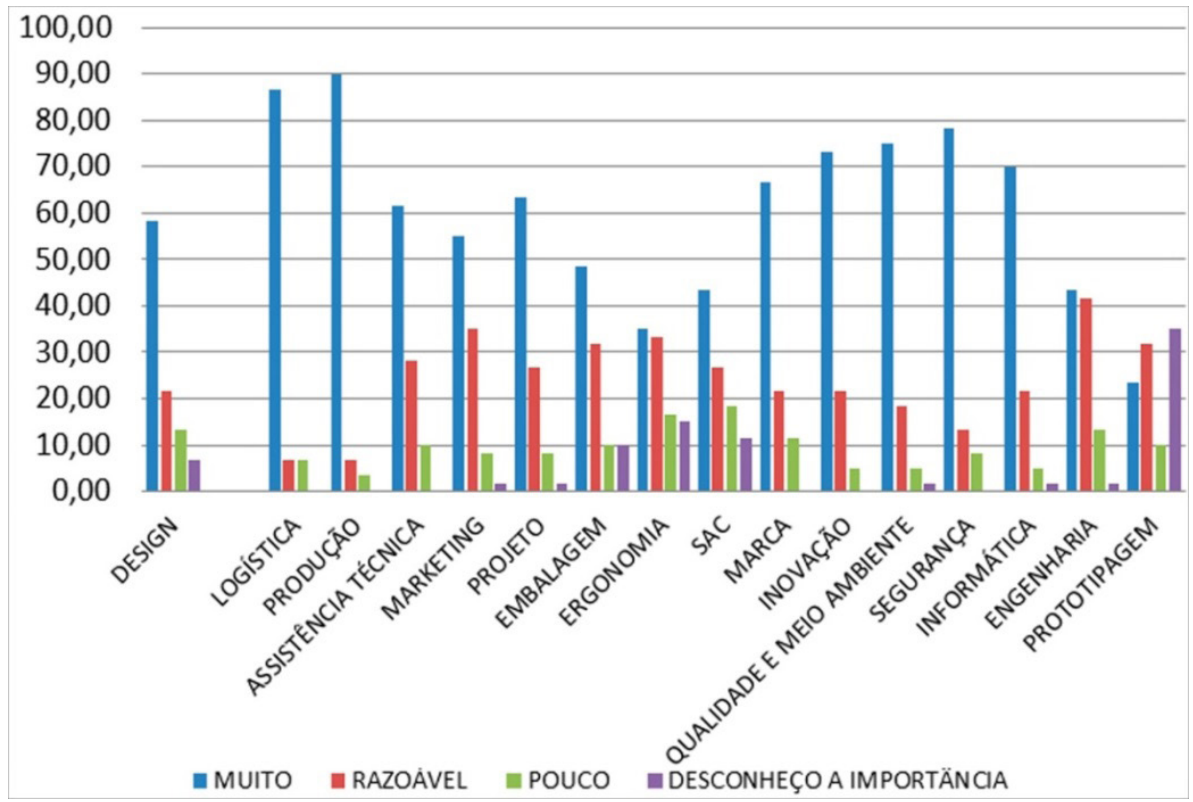

Fonte: Os autores, 2014. 
Os itens avaliados, de alguma forma estão relacionados ao design e a disparidade dos percentuais encontrados apontam, inicialmente, para um desconhecimento dessa atividade. Para melhor análise dessa questão, foram isolados 04 itens que estão relacionados diretamente ao processo de design dentro das indústrias juntamente com o item design, para melhor compreensão dos resultados (figura 3). Entre tais itens, apenas "projeto" obteve alto valor de importância (63,33\%). Os demais foram avaliados como razoável ou de pouca importância (ergonomia (50\%), engenharia (55\%) e prototipagem (41,67\%)). Destaca-se também o percentual elevado de empresas que desconhecem a ergonomia (15\%) e a prototipagem (35\%). Um aspecto a ser salientado sobre a prototipagem é que este processo apoia a indústria na elaboração de novos produtos, permitindo a redução do ciclo de desenvolvimento, acelerando o lançamento destes no mercado, e na pesquisa percebe-se que tal recurso ainda é pouco utilizado pelas indústrias do RN.

Os itens avaliados na figura 03 fazem parte do processo de projetação. Os resultados apontam que não são percebidos de maneira sistêmica no processo de projetação. Entretanto, o design é considerado muito importante por $58,33 \%$ das empresas, tais resultados corroboram com os dados disponíveis na literatura referida no capítulo 3 onde muitas empresas aparentemente desconhecem a dimensão da atividade design e os processos e ferramentas de gestão a ela relacionadas.

Figura 3 - Itens relacionados ao processo de design

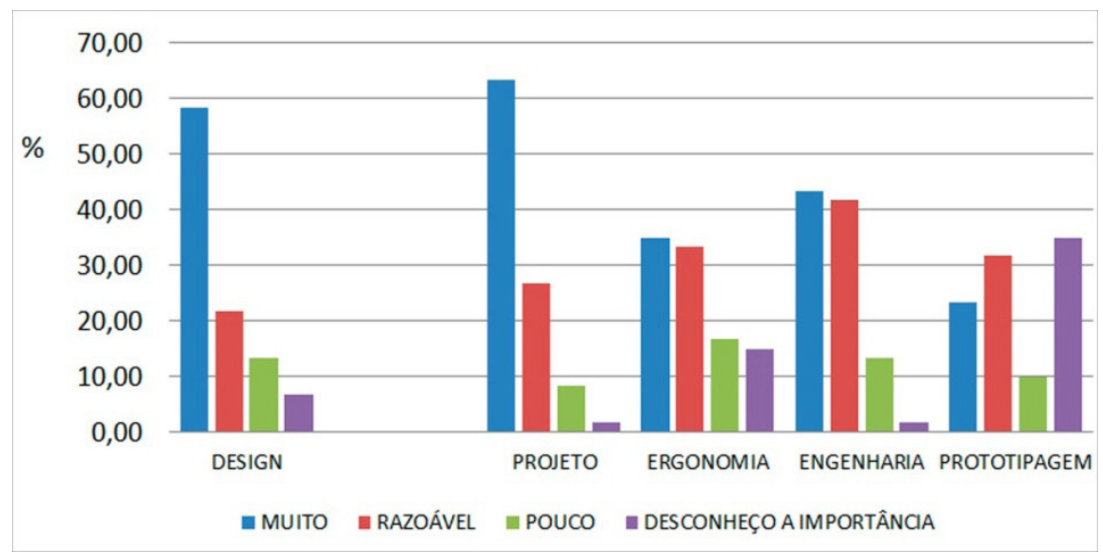

Fonte: Os autores, 2014.

Isolando o setor da construção civil (figura $4 \mathrm{~A}$ ), o resultado é diferente do geral. As empresas deste setor (54,55\%) consideram os itens relacionados ao design muito importantes, resultado $10 \%$ superior à média geral e nenhuma empresa desse setor afirma desconhecer a importância desses itens de projetação. Entretanto, percebe-se um alto grau de desconhecimento da atividade de design (18,18\%) aliada a baixa importância atribuída pelas empresas (41,81\%). Os resultados apontam para o desconhecimento do 
potencial e das vantagens competitivas do design, por parte das indústrias do setor da construção civil, o que pode leva-las a não perceberem a necessidade de investir em design.

No setor têxtil, verifica-se que $17,86 \%$ das empresas desconhecem a importância dos itens relacionados ao design, resultado expressivo para um setor cuja atividade impacta diretamente no desempenho competitivo das empresas (Figura 4 B).

Figura 4 - Itens relacionados ao processo de design ( $A$ - construção civil, B - têxtil, C - alimentício)

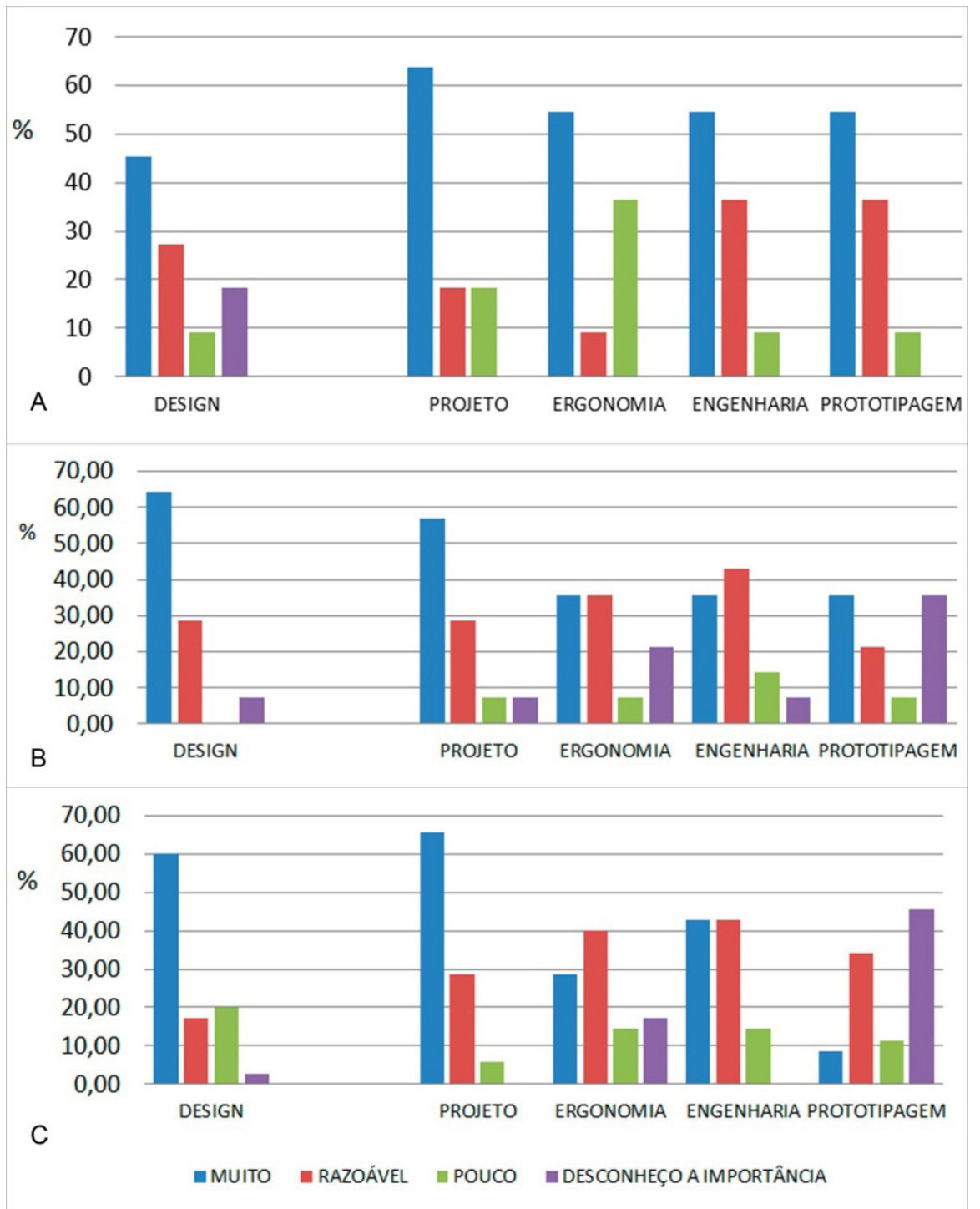

Fonte: Os autores, 2014.

As figuras $4 \mathrm{~B}$ e $\mathrm{C}$ mostram, respectivamente, os resultados dos setores Têxtil e Alimentício, que apresentaram diferenças significativas comparadas à construção civil. O setor alimentício (figura 4 C) apresentou resultados semelhantes ao têxtil, onde apenas $36,43 \%$ das empresas, consideram esses itens muito importantes (menor valor entre os três setores) e 15,72\% desconhecem sua importância. Apenas 38,75\% dos setores têxtil e alimentício, 
apontam os itens diretamente relacionados ao processo de design como muito importantes, ainda que a maioria (64,29\% e 60\% respectivamente) aponte o item design, isoladamente, como muito importante. Indicando que, apesar de algumas empresas identificarem o design como muito importante, estas desconhecem suas ferramentas de atuação.

\subsection{A Importância de Serviços e Técnicas para Agregar Valor aos Produtos}

Na pergunta seguinte (figura 05), as empresas foram abordadas de maneira a atribuem grau de importância, para seus respectivos negócios, atividades relacionadas a serviços e técnicas/ferramentas para adição de valores (tangíveis ou intangíveis) aos seus produtos. Tais atividades são amplamente utilizadas por empresas para o desenvolvimento de seus diversos projetos.

Figura 5 - Qual a importância dos seguintes serviços?

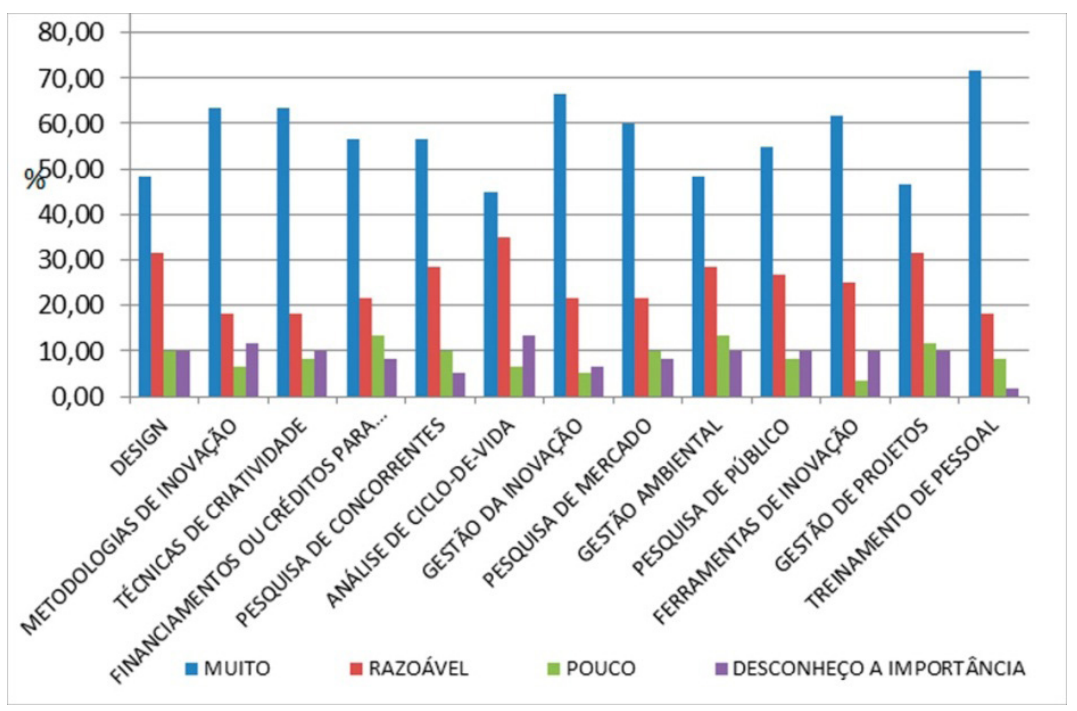

Fonte: Os autores, 2014.

Os serviços mais importantes apontados pelas empresas foram "Treinamento de pessoal" e "gestão da inovação" (71,67\% e 66,67\%). Os serviços "análise de ciclo-de-vida", "design" e "gestão ambiental" foram considerados muito importantes por menos da metade das empresas (45\%, $48,33 \%$ e $48,33 \%$ respectivamente) (figura 4 ). O que contradiz os resultados gerais (figura 2), visto que, de acordo com a etapa inicial da pesquisa) o item "qualidade e meio ambiente" foi considerado muito importante para 75\% das empresas, diferença de $26,67 \%$ com relação à "gestão ambiental" e 30\% a "análise do ciclo-de-vida". Os itens análise de "ciclo-de-vida" e "metodologias de inovação", apresentaram apenas 13,33\% e 11,67\%, respectivamente, apontando para seu desconhecimento. 
O item "design" é considerado muito importante por apenas 48,33\% das empresas, mas foi considerado pouco importante tanto para a indústria da construção civil, quanto para a alimentícia (figura 6). Observa-se uma diferença significativa à questão anterior, sendo o nível de importância do design consideravelmente maior quando esta atividade foi apresentada como algo tangível (58,33\%). O nível de desconhecimento também apresentou aumento, no total $10 \%$ das empresas apontam desconhecer o design quando este é abordado como um serviço. Estes resultados novamente apontam para o desconhecimento da atividade e sua abrangência e mais uma vez percebe-se a tendência de entender o design apenas como algo tangível.

Figura 6 - Serviços relacionados ao processo de design

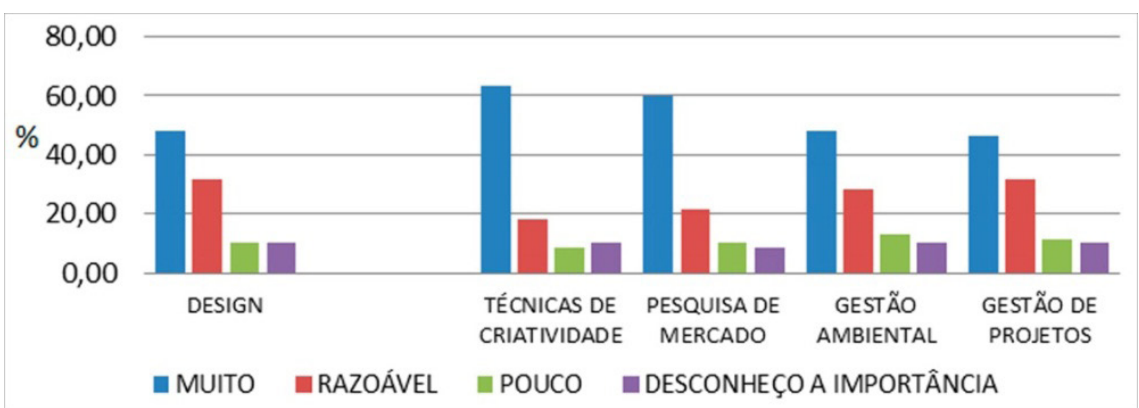

Fonte: Os autores, 2014.

Relacionada à importância do design para os três setores estudados, percebe-se que para a grande maioria das empresas do setor têxtil $(71,43 \%)$ essa atividade possui importância significativa, seguida do setor alimentício (42,86\%), enquanto apenas $36,36 \%$ do setor da construção civil considera essa atividade importante. Conforme discutido anteriormente, o design é uma das principais formas utilizadas pelas empresas para diferenciar seu produto, neste sentido, é possível apontar um grande potencial para sensibilização dessas empresas e incrementar sua competitividade via design.

Para melhor análise desse quesito, foram isolados serviços relacionados diretamente a atividade de design (técnicas de criatividade, gestão de projetos, pesquisa de mercado e gestão ambiental). Assim, 54,58\% das empresas (figura 6) percebe a importância desses serviços, percentual superior ao do item design (48,33\%). Observa-se considerável diferença entre design e técnicas de criatividade, este serviço é considerado muito importante por $63,33 \%$ das empresas, $15 \%$ superior ao serviço design. Gestão de projetos obteve o menor resultado, considerado muito importante por apenas $46,67 \%$ das empresas, em contraposto, pesquisa de mercado, serviço que compõe a gestão de projetos, é considerado muito importante por $60 \%$ das empresas. Gestão Ambiental, assim como design, é considerada muito importante para 48,33\% e ainda é desconhecida por $10 \%$ das empresas. Verifica-se, portanto, que os resultados apontam para não percepção do design para além do "desenho", visto que os demais serviços fazem parte da cadeia de valor do design. 
Quando analisados os serviços anteriores de acordo com cada setor, o resultado se difere. Pode-se verificar que a grande maioria das empresas do setor da construção civil (72,73\%), considera muito importante apenas à gestão de projetos (figura $7 \mathrm{~A}$ ). $\mathrm{O}$ que indica, conforme discutido anteriormente, que este setor não relaciona design com "gestão de projetos", visto que o primeiro é considerado muito importante por apenas 36,36\% das empresas. Esse setor também não considerou importantes "técnicas de criatividade", visto que apenas $36,36 \%$ percebe sua grande importância. Não valorizar técnicas de criatividade e design pode gerar perda na capacidade de inovação dessas empresas. Observa-se que com exceção do item "gestão de projetos", todos os demais obtiveram pouca importância. Percebe-se novamente a falta de relação entre o design e a gestão de projetos por parte das empresas deste setor. Enquanto para o setor da construção civil a gestão de projetos é o item mais importante, para o têxtil este item apresentou pouca importância, sendo considerado muito importante por apenas 35,71\%, ficando atrás dos demais itens. Ao analisar essa questão observou-se um nível de desconhecimento considerado alto para os itens selecionados $(12,50 \%)$, o maior entre os setores analisados (figura 7 B).

Verifica-se ainda que o setor têxtil considera o design um serviço de grande importância, pois atribui grande importância às técnicas de criatividade (71,43\%) e pesquisas de mercado (64,29\%), em detrimento da gestão de projetos (35,71\%). O que aponta para pouca percepção do processo projetual do design, uma vez que o projeto abrange todos os itens descritos. Outro item negligenciado é a "gestão ambiental", apenas 42,89\% consideram de grande importância. Apesar de "técnicas de criatividade" ser considerada importante pela maioria dos entrevistados, este item também obteve o maior desconhecimento $(21,43 \%)$, que pode ser considerado elevado em virtude das atividades deste setor, que lida diretamente com criação.

O setor alimentício (figura 7 C) em pouco diferiu do têxtil, ambos apontam "técnicas de criatividade" como item mais importante dentre os demais. O resultado mais divergente do setor têxtil para o de alimentos foi referente ao design. Embora este setor considere muito importante técnicas de criatividade (68,57\%), aparentemente estas técnicas não se relacionam ao design, uma vez que design obteve alto nível de importância atribuída por apenas $42,86 \%$ das empresas, sendo este percentual $22,85 \%$ inferior quando o design é abordado como algo tangível e não como serviço. Mais uma vez observa-se a percepção limitada da atividade. Os itens gestão ambiental e gestão de projetos, apresentaram baixos índices de importância para os setores têxtil e alimentício, resultado divergente do setor da construção civil. 
ALVES, Cristiano et al.

Figura 7 - Serviços relacionados ao processo de design

A - construção civil, B - têxtil, C alimentício
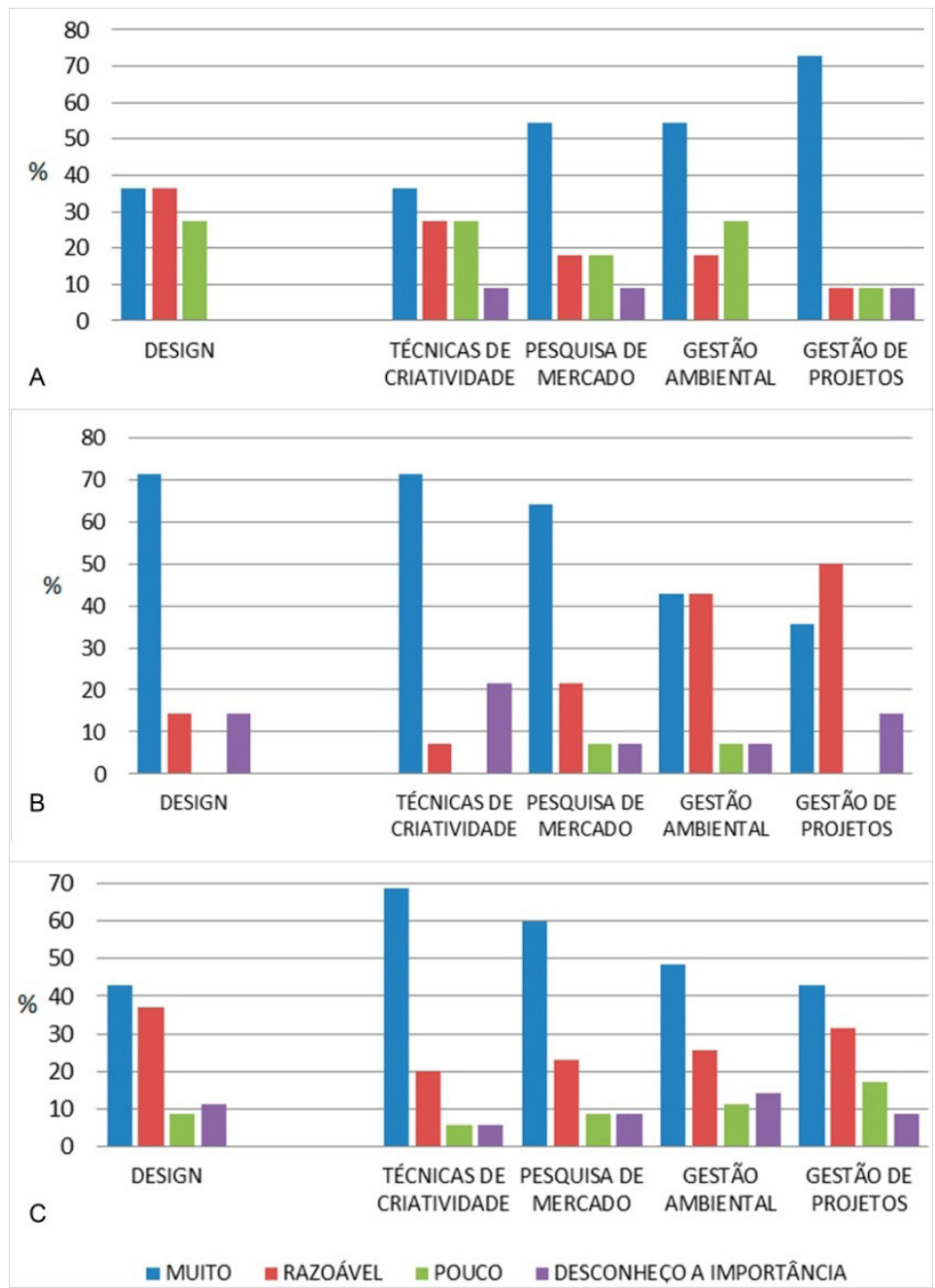

Fonte: Os autores, 2014.

\subsection{Abrangências dos Produtos Oferecidos}

Com o intuito de analisar o grau de compreensão das empresas em relação a abrangência de seus respectivos produtos e perceber o potencial do design em promover inovação e incremento da competitividade, as empresas foram abordadas a informar qual o tipo de produto/serviço oferecem ao mercado (figura 8).

Figura 8- Qual o tipo de produto fornecido pela sua empresa?

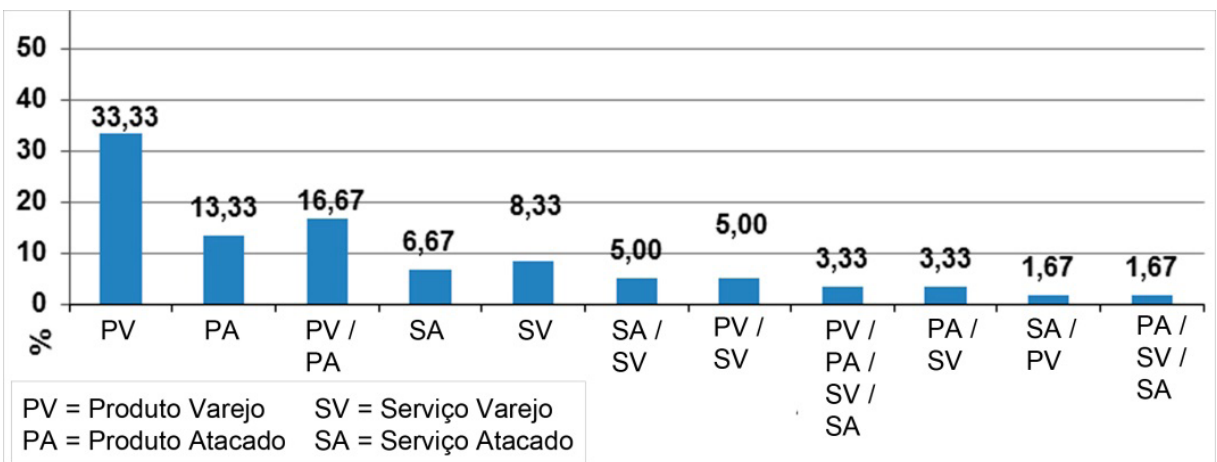

Fonte: Os autores, 2014.

Projética, Londrina, v.8, n.2, p. 127-143, Jul./Dez. 2017 
Os resultados ilustram que a maioria das empresas percebe seu produto apenas como um objeto tangível, visto que 63,33\% consideram apenas comercializarem produtos (tangíveis), sejam de atacado ou de varejo. Por outro lado, todos os itens que possuem serviço entre as opções foram apontados por menos de $30 \%$ das empresas. O fato de perceberem apenas a tangibilidade dos seus produtos pode se tornar entrave à capacidade de inovação e competitividade. Portanto, o design pode atuar na gestão do portfólio dessas empresas e ampliar sua possibilidade de negócio, agregando diferentes valores aos seus produtos.

\subsection{Dimensão das Atividades do Design}

Objetivando identificar a compreensão das empresas sobre a dimensão do design, estas foram solicitadas a apontar sua compreensão sobre a abrangência das atividades desempenhadas pelo design, havendo a possibilidade de escolha de mais de uma alternativa. A partir dos resultados foi possível perceber que muitas empresas desconhecem o universo de atividades na qual o design pode inferir para agregar valor ao negócio. Na figura 9, pode-se observar que nenhuma das empresas assinalou o design como uma atividade que envolva todas as escolhas (processo, gestão e estética). Assim, percebe-se que ainda existe a visão ultrapassada dessa atividade, visto que o design é um processo macro, na medida em que atinge diversos níveis (estratégico, tático e operacional) e áreas dentro de uma organização (projeto e desenvolvimento de produto, marketing, engenharia e produção) (TEIXEIRA, 2005).

Tais resultados corroboram com os resultados anteriores, apontando a não compreensão do design, visto que as empresas não o percebem como sistêmico, ou seja, que o design envolve desde a política de tomada de decisões das empresas até o projeto do produto final das mesmas. E, como apontado na figura 9 o design e a sua gestão são percebidos como atividades separadas e não sinérgicas. Ainda na figura 12 é possível observar que os resultados variam de acordo com o setor. A figura ilustra que $50 \%$ das empresas do setor têxtil consideram o design como atividade de gestão, 28,57\% atividade de estética, $14,29 \%$ atividade de processo e $7,14 \%$ desconhecem essa atividade. Percebe-se que mesmo a estética sendo de grande importância para este setor, não foi o item de maior destaque. Ainda, o percentual de desconhecimento do design pode ser considerado elevado, maior inclusive do que o setor de alimentos $(2,86 \%$, figura 10), devido suas atividades serem muito influenciadas pelo design. Entre as empresas do setor têxtil nenhuma (0\%) apontou mais de uma atuação do design, ou seja, percebem o design como uma "ferramenta" de abrangência limitada. Observa-se que embora o setor tenha atribuído grande importância ao design, (figuras 4 e 9), a abrangência da atividade é ainda desconhecida, gerando incoerência às respostas anteriores. 
Figura 9 - Para sua empresa, o que é design?

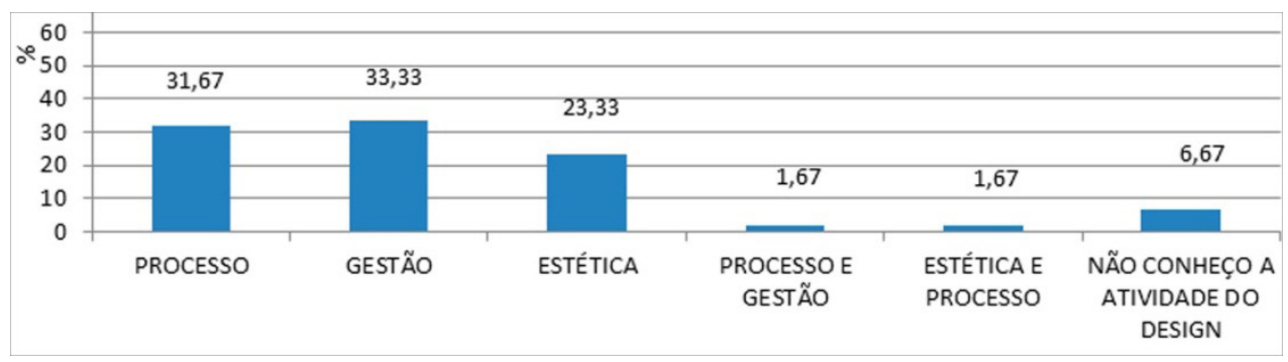

Fonte: Os autores, 2014.

Comparado o resultado da questão de design entre as indústrias têxtil com a indústria de alimentos e de construção civil, a visão do têxtil diferenciada. Enquanto para a indústria têxtil o design é, majoritariamente, atividade de gestão e em seguida atividade de estética, para as indústrias da construção civil e de alimentos é considerada como atividade de processo (36,4\% e $37,14 \%$, respectivamente). Referente à indústria da construção esse resultado se relaciona com as atividades do setor, demasiado operacional e pragmático.

Figura 10 - Design - setor têxtil, alimentício e construção civil.

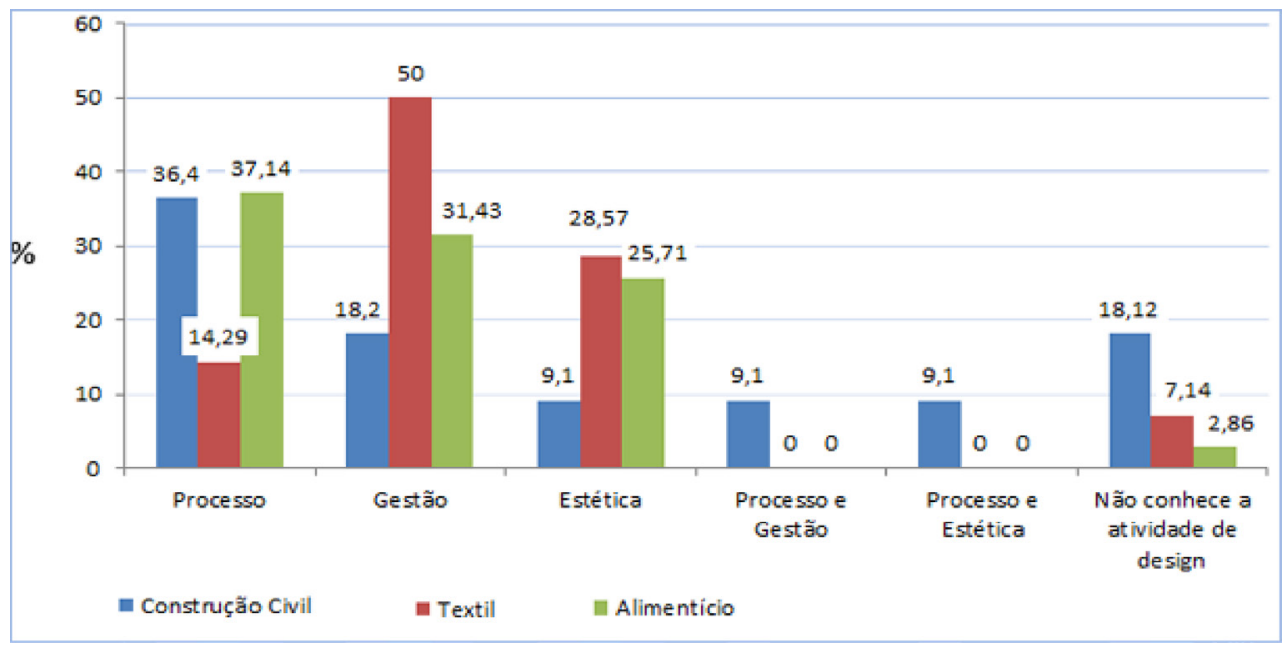

Fonte: Os autores, 2014.

As empresas da construção civil apontaram o maior índice de desconhecimento (18,2\%) entre os três setores (figura 10). Apesar do alto desconhecimento, foi o único setor em que parte das empresas apontam mais de uma alternativa, ou seja, 9,1\% percebem o design como atividade de processo e gestão e como estética e processo. O que não condiz com a realidade da atividade, mas se aproxima da realidade do design, visto que a abrangência vai desde a concepção do produto até a entrega ao cliente. Assim, a atuação do design ultrapassa a criação de produtos como elementos isolados, passando a ser parte de um sistema e consolidando-se como um processo de gestão.

O setor alimentício apresentou resultados semelhantes à construção civil, entretanto, apenas uma opção foi assinalada pelas empresas (figura 9). Para o setor design é considerado uma atividade de processo (37,14\%). 
Contudo, é possível observar equilíbrio nos resultados, visto que para 31,43\% e $25,71 \%$ o design é, respectivamente, gestão e estética.

\section{CONCLUSÃO}

O design tem se destacado nas últimas décadas no mercado brasileiro, mas no RN os resultados indicam que as empresas dos setores alimentício, têxtil e construção civil não percebem a atividade como estratégica. Observa-se na figura 9 que as empresas não compreendem o design como atividade sistêmica, abrangendo toda a pirâmide de decisões (desde a política de tomada de decisões até o projeto do produto final). Para essas empresas, o design é percebido como atividades separadas, não sinérgicas. Mesmo considerando a inovação como algo importante, muitas empresas desconhecem a atividade de design, desconhecendo também outras atividades referentes ao processo de inovação, como foi possível identificar no capitulo 5.2 (figuras 5 - 7). Apontando assim a inovação como discurso retórico, não encontrando suporte nas ações dessas empresas o que pode ser verificado nas figuras 3 e 4, que apontam a limitada percepção dessas empresas sobre processos que colaboram diretamente com o processo de inovação (projeto, ergonomia, engenharia e prototipagem). Tais resultados corroboram com Teixeira (2005) que afirma que o empresário relega o design por não conseguir visualizá-lo dentro de um planejamento estratégico, por não entender o seu plano de ação ou a forma como este deverá ser gerido na empresa.

Outro aspecto importante identificado na pesquisa, está relacionado a percepção limitada das empresas sobre a abrangência de seus produtos (figura 8), compreendendo-os apenas como algo tangível (manufaturado), reduzindo assim potenciais ações estratégicas de inovação, principalmente, relacionadas a serviços agregados aos produtos. Nesse aspecto, o design possui competências para colaborar com as empresas incrementando suas capacidades criativas e, de maneira estratégica, tornar explicito novos mercados para seus produtos.

Este trabalho permite verificar uma vasta demanda reprimida, referente ao processo de inovação nas empresas do RN, implicando em grande potencial de atuação do design no incremento dos produtos e da economia local, possibilitando o aumento da competitividade das mesmas. Para que a percepção do design e suas vantagens estratégicas sejam abrangentes, neste caso, é necessário difundir a cultura do design e seus benefícios, desenvolvendo ações de sensibilização a respeito das atividades desempenhadas pelo design e sua ligação com processos de inovação. Apesar de focado no panorama empresarial do estado do RN, esse trabalho permite estimar um panorama regional, uma vez que diversos estados da região Nordeste do Brasil possuírem baixos índices de industrialização e desenvolvimento de inovação. Tal constatação coopera com a área do design, fornecendo dados que contribuem com possíveis ações para 
criação da cultura do design nessa região. Assim, destaca-se a necessidade de se prosseguir com pesquisas e desenvolvimento, no intuito de propor métodos de inserção do design nas indústrias da região.

\section{REFERÊNCIAS}

BENAVIDES, Puerto Henry. Design e inovação tecnológica: coletâneas de ideias para construir um discurso. Salvador: IEL/ FIEB, 1999.

BONSIEPE, Gui. Design do Material do Digital. São Paulo: Blucher, 2015.

CONFEDERAÇÃO NACIONAL DA INDÚSTRIA. A importância do design para sua empresa. Brasília: CNI, 1998.

FEDERAÇÃO DAS INDÚSTRIAS DO ESTADO DO RIO GRANDE DO NORTE. Indicadores básicos e indústria. Natal: FIERN, 2012.

MARQUES, Carolina de Oliveira. O ensino e o mercado de trabalho na área de design. 2010. 104 f. Dissertação (Mestrado em Design) - Faculdade de Arquitetura, Artes e Comunicação, Universidade Estadual Paulista "Júlio de Mesquita Filho", Bauru, 2010.

MOZOTA, Brigitte Borja de. Design Management. New York: Allworth, 2003.

MOZOTA, Brigitte Borja de; KLÖPSCH, Cássia; COSTA, Felipe Campelo Xavier da. Gestão de Design: usando o design para construir valor de marca e inovação corporativa. Porto Alegre: Bookman, 2011.

RAULIK, Gisele. Models for Design Advisory Service: the rapport between design organizations and SMEs. Dissertation (Master in Design Strategy and Innovation) - Design Strategy and Innovation Program, Brunel University, United Kingdom, 2003.

REDE DESIGN BRASIL. Design degrau por degrau. 2005. Disponível em: $<$ http://www.designbrasil.org.br/artigo/design-degrau-por-degrau>. Acesso em:

SEBRAE. Boletim estatístico de micro e pequenas empresas. Brasília: SEBRAE, 2005. 
TEIXEIRA, Joselena de Almeida. O design estratégico na melhoria da competitividade das empresas. 2005. 270 f. Tese (Doutorado em Engenharia de Produção) - Universidade Federal de Santa Catarina, Florianópolis, 2005.

Submissão: 09-2016

Aceite: 10-2016 